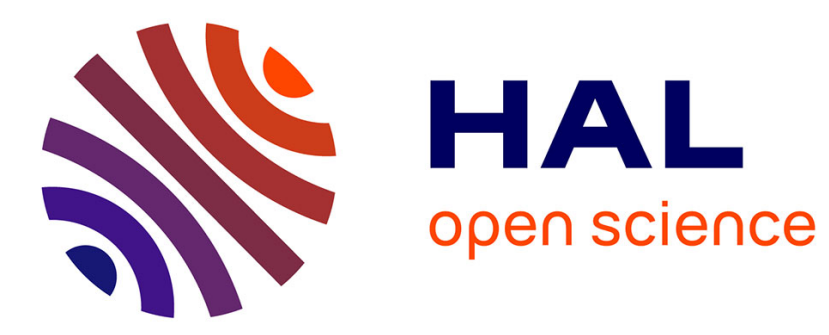

\title{
Single and multiple fragmentation of brittle geomaterials
}

François Hild, Pascal Forquin, Ana Rita Cordeiro da Silva

\section{To cite this version:}

François Hild, Pascal Forquin, Ana Rita Cordeiro da Silva. Single and multiple fragmentation of brittle geomaterials. Revue Française de Génie Civil , 2003, 7, pp.973-2003. hal-00002911

\section{HAL Id: hal-00002911 \\ https://hal.science/hal-00002911}

Submitted on 20 Sep 2004

HAL is a multi-disciplinary open access archive for the deposit and dissemination of scientific research documents, whether they are published or not. The documents may come from teaching and research institutions in France or abroad, or from public or private research centers.
L'archive ouverte pluridisciplinaire HAL, est destinée au dépôt et à la diffusion de documents scientifiques de niveau recherche, publiés ou non, émanant des établissements d'enseignement et de recherche français ou étrangers, des laboratoires publics ou privés. 


\title{
Single and multiple fragmentation of brittle geomaterials
}

\author{
François Hild $^{1}$ - Pascal Forquin ${ }^{1,2}$ - Ana Rita Cordeiro da \\ Silva
}

${ }^{1}$ LMT-Cachan, ENS de Cachan / CNRS-UMR 8535 / Université Paris 6 61 avenue du Président Wilson, F-94235 Cachan Cedex, France

hild@lmt.ens-cachan.fr

${ }^{2}$ DGA/CTA-Département MSP

16 bis avenue Prieur de la Côte d'Or, F-94114 Arcueil Cedex, France

pforquin@etca.fr

${ }^{3}$ Department of Structural Engineering, São Carlos School of Engineering

University of São Paulo, Avenida do Trabalhador São Carlense, 400

13560-590 São Carlos, SP, Brazil

RÉSUMÉ.L'endommagement et la rupture de matériaux à comportement fragile ou quasifragile est analysé ici. Un accent particulier est mis sur la discrimination entre descriptions discrète et continue de l'endommagement et de la rupture. Les matériaux analysés sont des bétons, ciments et roches.

ABSTRACT. The degradation and failure of brittle or quasi-brittle geomaterials are analyzed in this Lecture. The main emphasis is put on the discrimination between discrete and continuum approaches to describe damage and fracture. The materials studied herein are cement, highperformance concrete and rocks.

MOTS-CLÉS : Rupture fragile, comportement quasi-fragile, approche probabiliste, mécanique de l'endommagement, ciment, béton, roche.

KEYWORDS: Brittle fracture, quasi-brittle behavior, probabilistic approach, Continuum Damage Mechanics, cement, concrete, rock.

Nom de la revue. Volume $\mathrm{X}-\mathrm{n}^{\circ} \mathrm{X} / 2002$, pages 1 à $\mathrm{X}$ 


\section{Examples of geomaterials undergoing single and/or multiple fragmentation}

The single or multiple fragmentation in brittle geomaterials (e.g., cement, concrete and rocks) is analyzed herein. This mechanism is the key to model damage and failure in these materials. Single fragmentation is observed in many brittle materials when the stress rate is low. It follows that a weakest link hypothesis can be made (Freudenthal, 1968) and a Weibull model $(1939 ; 1951)$ is used to fit experimental data (Fig. 1)

$$
P_{F}=1-\exp \left[-Z_{e f f} \lambda_{t}\left(\sigma_{F}\right)\right] \text { with } \lambda_{t}\left(\sigma_{F}\right)=\lambda_{0}\left(\frac{\sigma_{F}}{\sigma_{0}}\right)^{m}
$$

where $P_{F}$ denotes the failure probability, $\sigma_{F}$ the failure stress (i.e., the maximum value of any suitable equivalent stress), $Z_{\text {eff }}$ the effective volume, surface or length (Davies, 1973), $\lambda_{t}$ the corresponding defect density, $m$ the Weibull modulus, $\sigma_{0}$ a scale parameter relative to a reference density $\lambda_{0}$. The constant $\sigma_{0}^{m} / \lambda_{0}$ is the Weibull scale parameter. In the following, when no special mention is made, the development is valid for any space dimension $n$ (i.e., 1, 2 or 3). Otherwise, it will be clearly stated for which space dimension the results are valid.

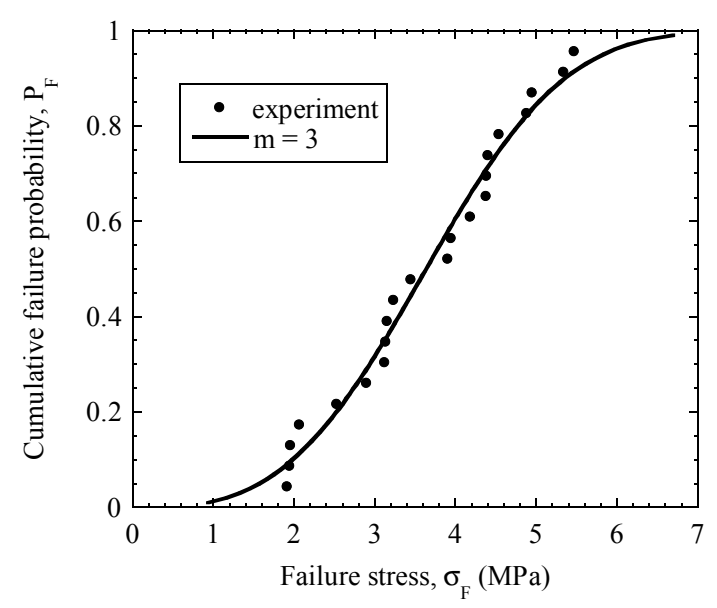

Figure 1. Cumulative failure probability vs. failure stress for limestone in a series of 22 three-point flexural tests. Best fit with a Weibull model $(m \approx 3)$. 
It can be noted that the previous formulation [i.e., Eq. (1)] enters the framework of a Poisson point process of intensity $\lambda_{t}$ (Gulino et al., 1991; Jeulin, 1991). The material microstructure is therefore approximated by point defects of density $\lambda_{t}$ with random locations.

Since the pioneering work of Rinehart (1965), it is known that the ultimate strength of rocks under so-called dynamic loading conditions exceeds the static strength by as much as one order of magnitude. The distinct zones resulting from rock blasting were clearly identified by Kutter and Fairhurst (1971), namely a comminuted area in the vicinity of the explosive followed by a damaged zone in which dense microcracking is observed and finally a zone where few long cracks develop (Fig. 2). Later, it was recognized that inherent flaws are activated, can grow and eventually coalesce to form macrocracks (Shockey et al., 1974). Similarly, concrete can experience multiple fragmentation when hit by a projectile (Kennedy, 1976). Yet, when loaded in tension or flexure under quasi-static conditions, the same materials usually experience single fragmentation and their failure strength is no longer deterministic (Fig. 1).

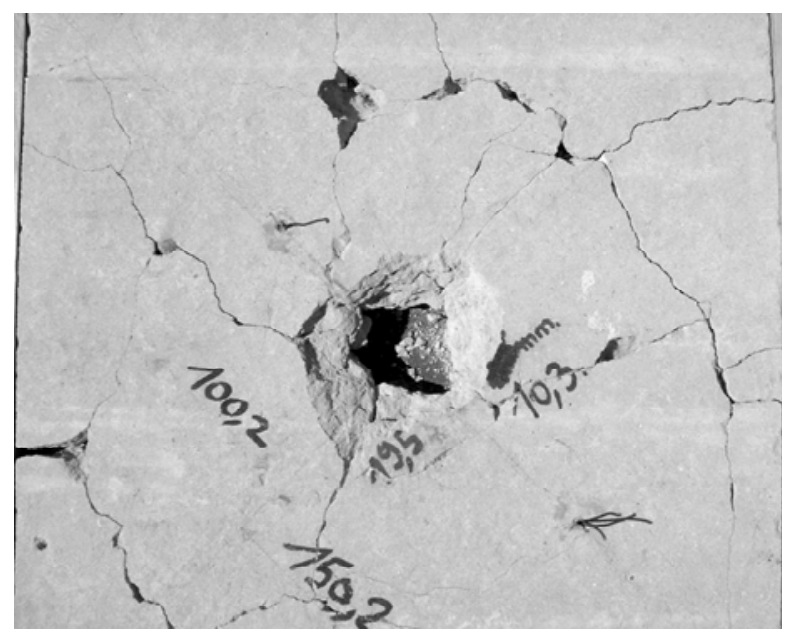

Figure 2. Fragmentation of Beaucaire limestone caused by a blast. A fully fragmented 30-mm zone around the hole is accompanied with larger parts where long cracks develop [after Grare (2002)]. 
Consequently, the question to address is to choose between a discrete or continuum description of damage. Section 2 deals with a discrete approach of fracture in brittle materials. The aim of Section 3 is to show the link between a discrete analysis of the fragmentation process under dynamic loading conditions and an extended constitutive equation written in the framework of Continuum Damage Mechanics (CDM).

\section{Fragmentation of geomaterials under quasi-static loading}

Under quasi-static loading condition, a weakest link hypothesis can be made. It follows that a probabilistic model needs to be used. In the sequel, the Weibull model is introduced and applied to different geomaterials.

\subsection{Initial defects and brittle fracture}

In brittle materials, failure is caused by unstable growth of cracks induced by defects (or heterogeneities), which are randomly distributed. Let us consider an initial flaw size distribution $f_{0}$ that depends upon morphological parameters. For the sake of simplicity, initial defects are modeled as penny-shaped cracks whose normal is aligned with the local maximum principal stress direction. The elementary failure probability $P_{F 0}$ is expressed as

$$
P_{F 0}=\int_{a_{c}}^{+\infty} f_{0}(a) d a
$$

where $a_{c}$ is the critical crack size $\left[\sqrt{ } a_{c}=K_{c} / Y \sigma_{1}, \sigma_{1}\right.$ is the maximum principal stress, $K_{c}$ the toughness and $Y$ a dimensionless parameter]. By assuming that the defect distribution is characterized by a Poisson point process in the framework of a weakest link hypothesis, the cumulative failure probability $P_{F}$ of a structure $\Omega$ is related to $P_{F 0}$ by

$$
P_{F}=1-\exp \left[-\lambda_{0} \int_{\Omega} P_{F 0} d Z\right],
$$

where $\lambda_{0}$ corresponds to a reference defect density per unit volume, surface or length [see Eq. (1)]. 


\subsection{Correlation with a Weibull model}

Let us assume that the flaw size distribution is approximated by a power law function (Jayatilaka et al., 1977) for the large sizes

$$
f_{0}(a) \approx \frac{(p-1)}{a_{0}}\left(\frac{a}{a_{0}}\right)^{-p}
$$

where $p$ and $a_{0}$ are material parameters. The elementary failure probability can be rewritten as

$$
P_{F 0}=\left(\frac{a_{c}}{a_{0}}\right)^{-p+1}=\left(\frac{\sigma_{1}}{\sigma_{0}}\right)^{2(p-1)},
$$

where $\sigma_{0}=K_{c} / Y \sqrt{ } a_{0}$, and one ends up with a two-parameter Weibull law (1939; 1951)

$$
P_{F}=1-\exp \left[-\lambda_{0} \int_{\Omega}\left(\frac{\left\langle\sigma_{1}\right\rangle}{\sigma_{0}}\right)^{m} d Z\right]
$$

where $\langle$.$\rangle are the Macauley brackets, m=2(p-1)$ and $\sigma_{0}^{m} / \lambda_{0}$ are the two Weibull parameters that are related to the flaw size distribution. By using similar hypotheses (Hild et al., 1992b), a three-parameter Weibull law can be obtained

$$
P_{F}=1-\exp \left[-\lambda_{0} \int_{\Omega}\left(\frac{\left\langle\sigma_{1}-\sigma_{u}\right\rangle}{\sigma_{0}}\right)^{m} d Z\right],
$$

where $m, \sigma_{u}$ and $\sigma_{0}^{m} / \lambda_{0}$ are the three Weibull parameters.

\subsection{Generalized Weibull model}

The previous results can be generalized when initial defects are modeled by penny-shaped cracks of radius $a$ whose orientation is uniformly distributed (Hild, 2001). With a mode I failure condition, the original Weibull model (1939) is obtained. It is worth noting that the equivalent stress chosen by Weibull corresponds to an assumption of a mode I mechanism of failure (even though this concept was not yet discovered). Other models enter the same framework. Of those, 
one may mention the model developed by Batdorf and Crose (1974). Lastly, the model proposed by Evans and Lamon (1978; 1983) uses yet another failure criterion. The key distinction between the three models is given by the failure criterion (Hild, 1998).

\subsection{First case study: DVH effects}

For a two-parameter Weibull law [see Eq. (6)], the cumulative failure probability can be written as

$$
P_{F}=1-\exp \left[-\lambda_{0} Z H_{m}\left(\frac{\left\langle\sigma_{F}\right\rangle}{\sigma_{0}}\right)^{m}\right] \text { with } \sigma_{\mathrm{F}}=\max _{\Omega} \sigma_{1}
$$

where a stress heterogeneity factor $H_{m}$ (Hild et al., 1992a) can be expressed as

$$
H_{m}=\frac{1}{Z} \int_{\Omega}\left(\frac{\left\langle\sigma_{1}\right\rangle}{\sigma_{F}}\right)^{m} d Z \text { when } \sigma_{F}>0
$$

The stress heterogeneity factor characterizes the effect of the load pattern on the cumulative failure probability. From a probabilistic perspective, it characterizes the fact that a defect is critical when it is large enough in a zone loaded significantly. An effective volume, surface or length $Z_{\text {eff }}$ can be defined as (Davies, 1973)

$$
Z_{\text {eff }}=Z H_{m}
$$

When the latter is loaded in pure tension (i.e., $H_{m}=1$ ), it would lead to the same failure probability as the considered domain $\Omega$ subjected to any loading condition. Finally, the average failure stress $\sigma_{\mathrm{av}}$ can be written as

$$
\sigma_{\mathrm{av}}=\sigma_{0}\left(\lambda_{0} Z H_{m}\right)^{-1 / m} \Gamma\left(1+\frac{1}{m}\right),
$$

and the corresponding standard deviation $\sigma_{\mathrm{sd}}$

$$
\sigma_{\mathrm{sd}}=\sigma_{0}\left(\lambda_{0} Z H_{m}\right)^{-1 / m} \sqrt{\Gamma\left(1+\frac{2}{m}\right)-\Gamma^{2}\left(1+\frac{1}{m}\right)},
$$

where $\Gamma$ is the Euler function of the second kind (Abramowitz et al., 1965). These last two equations illustrate the DVH effects: 
- D effect. The Weibull parameters $m=2(p-1)$ and $\sigma_{0}^{m} / \lambda_{0}$ are related to the flaw size distribution (see Section 2.2). The average strength and the corresponding standard deviation are directly linked with these parameters. However, the coefficient of variation $\sigma_{\mathrm{sd}} / \sigma_{\mathrm{av}}$ only depends upon the Weibull modulus $m$.

- V Effect. The larger the loaded volume (surface or length), the smaller the mean strength (Kadlecek et al., 1967; L'Hermite, 1973) and the corresponding standard deviation. This result shows that when extrapolated to real structures, there is a correction to be applied from data obtained from experiments performed in the laboratory.

- H Effect. The more heterogeneous the stress field, the smaller the stress heterogeneity factor $H_{m}$, the larger the mean strength. It follows that brittle materials are very sensitive to the type of loading (L'Hermite, 1973).

\subsection{Parameter identification}

For a two-parameter Weibull law, the identification procedure is straightforward. It consists in recasting Eq. (6) in the following form

$$
\ln \left[-\ln \left(1-P_{F}\right)\right]=m \ln \left(\sigma_{F}\right)+\ln \left(\frac{\lambda_{0} V H_{m}}{\sigma_{0}^{m}}\right) .
$$

Therefore, in a Weibull plot (1939) $\ln \left[-\ln \left(1-P_{F}\right)\right]$ vs. $\ln \left(\sigma_{F}\right)$, it is expected that the material data follow a straight line whose slope corresponds to the Weibull modulus $m$. Once the Weibull modulus $m$ is identified, the stress heterogeneity factor $H_{m}$ can be computed by using Eq. (9) and then by knowing the intercept, the scale parameter $\sigma_{0}^{m} / \lambda_{0}$ can be determined. One can note that a conventional least squares method can be utilized to tune the Weibull parameters. For a threeparameter Weibull law, a least squares method can be used as well. However, the identification procedure is not as simple as the previous one. It is worth mentioning that a maximum likelihood procedure is also well suited for the identification of statistical distributions such as the Weibull model (Munz et al., 1999). 


\subsection{Application to microconcrete and rock}

Microconcrete samples are made of materials with special proportions ( 1 volume of cement, 2.67 volumes of sand, 1.33 volumes of aggregates and 0.80 volume of water) so that the strength is sufficiently low for panels to be analyzed hereafter (i.e., with a low fiber volume fraction). Furthermore, the sand distribution is controlled and an average size of $0.6 \mathrm{~mm}$ is obtained. Similarly, the size distribution of aggregates is measured and an average of $2.8 \mathrm{~mm}$ is found. The average compressive strength of 3 standard samples (diameter: $10 \mathrm{~mm}$, height: 28 $\mathrm{mm}$ ) tested 41, 69, 97 and 132 days after casting is equal to $-17.5 \mathrm{MPa}$, whereas the average value of Young's modulus is equal to $19 \mathrm{GPa}$ (Silva, 2002). Four series of experiments have been carried out on microconcrete samples. Two different sample sizes, namely $25 \times 25 \times 170 \mathrm{~mm}^{3}$ and $25 \times 25 \times 320 \mathrm{~mm}^{3}$, and two different types of loadings, namely three-point flexure (outer span: $150 \mathrm{~mm}$ and $300 \mathrm{~mm}$, respectively) and four-point flexure (outer span: $150 \mathrm{~mm}$ and $300 \mathrm{~mm}$, respectively, inner span: $50 \mathrm{~mm}$ and $100 \mathrm{~mm}$, respectively) have been considered. Each set of experiments can be analyzed separately to determine the corresponding Weibull parameters. To perform the identification, the stress heterogeneity factors are computed by using Eq. (9) for a beam theory solution in four-point flexure (outer span / inner span $=2$ )

$$
H_{m}=\frac{1}{6(m+1)}+\frac{1}{3(m+1)^{2}},
$$

and three-point flexure

$$
H_{m}=\frac{1}{2(m+1)^{2}} .
$$

A reasonable agreement can be obtained (i.e., a correlation coefficient at least equal to 0.96 ) when each set of tests is analyzed separately (Silva, 2002). Since all the data will be considered as one series, only one set of Weibull parameters is used to describe the failure properties of the material. An initial Weibull modulus is needed (e.g., $m=5.3$ ) so that the Weibull stresses (Beremin, 1983)

$$
\sigma_{\mathrm{w}}=\sigma_{F}\left(\lambda_{0} Z H_{m}\right)^{-1 / m}
$$

for each experimental point can be determined by computing the effective volume $\mathrm{ZH}_{m}$. The stresses are then arranged in ascending order and a new identification of the two Weibull parameters is possible. For any of the four Weibull moduli taken 
as initial value, two iterations are needed to converge to the following values: $m=7.3$ and $\sigma_{0}=4.0 \mathrm{MPa}$ (with $1 / \lambda_{0}=20 \mathrm{~cm}^{3}$ ). It can be noted that these values are very close to the average obtained for the four sets of experiments [i.e., $m=7.3$ and $\sigma_{0}=4.1 \mathrm{MPa}$ (with $1 / \lambda_{0}=20 \mathrm{~cm}^{3}$ )]. Figure 3 shows the results obtained with this procedure in which all the data are considered simultaneously. A very good agreement is obtained (i.e., a correlation coefficient greater than 0.99). This analysis allows us to conclude that the Weibull model leads to reasonable estimates of the failure properties of the microconcrete studied herein for effective volumes varying between $0.68 \mathrm{~cm}^{3}$ (i.e., small samples loaded in 3-point flexure) and $4.67 \mathrm{~cm}^{3}$ (i.e., large samples loaded in 4-point flexure).

Limestone is also analyzed within the present framework. The rocks are extracted from the Beaucaire quarry. Samples of size $50 \times 50 \times 300 \mathrm{~mm}^{3}$ are loaded in three-point flexure (outer span: $250 \mathrm{~mm}$ ).
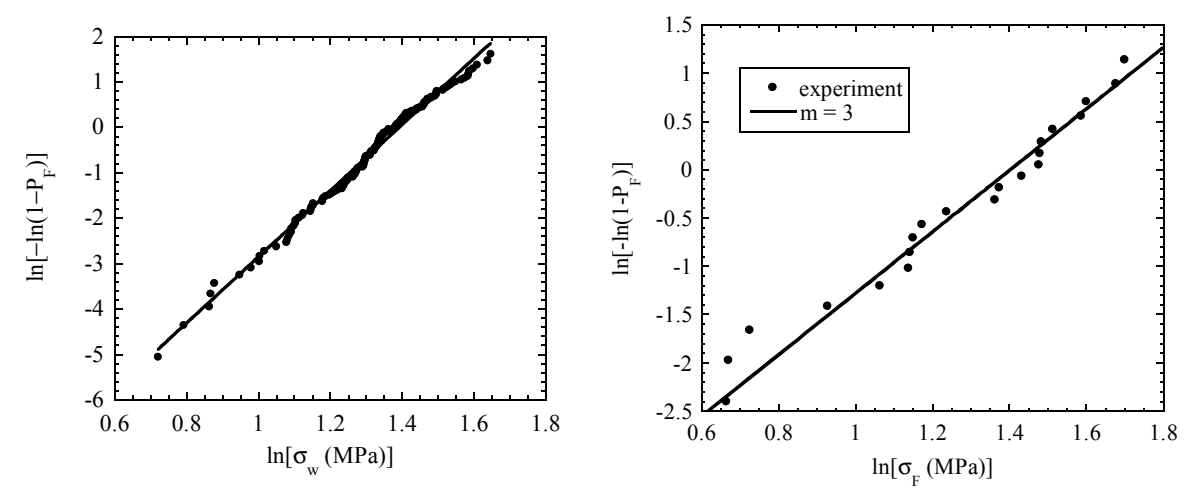

Figure 3. Modified Weibull plot for a Figure 4. Weibull plot for limestone in a microconcrete. Best fit with a Weibull series of three-point flexural tests. Best model $(m \approx 7.3)$. $\quad$ fit with a Weibull model $(m \approx 3)$.

The results of Fig. 1, corresponding to 22 experiments are recast in a Weibull plot (Fig. 4). The Weibull parameters are close to those identified directly, namely $m \approx 3$ and $\sigma_{0}=4 \mathrm{MPa}$ when $1 / \lambda_{0}=19 \mathrm{~cm}^{3}$ (i.e., identical to the effective volume). The low value of the Weibull modulus $m$ is an indication of a big scatter in terms of failure strength, to be expected for this type of geomaterial. 


\subsection{Second case study: high performance concrete}

High performance concrete is analyzed in the sequel. This material (powder reaction concrete, commercial name: $\mathrm{DUCTAL}^{\circledR}$ ) has a very fine microstructure made of components of different sizes (Fig. 5a), namely, fine quartz sand aggregates, cement, crushed quartz and silica fume (Richard et al., 1995). For the sake of simplicity, the results reported herein only concern fiber-free matrices for which a high compressive strength can be achieved but with a ductility comparable to conventional mortar. When reinforced by fibers, these materials can achieve values of the order of $-200 \mathrm{MPa}$ to $-800 \mathrm{MPa}$ in uniaxial compression (Dugat et al., 1996). A residual porosity of the order of $2 \%$ is obtained in the present case (i.e., when containing short fibers, the compressive strength is equal to $-200 \mathrm{MPa}$ ). The latter is the likely cause of failure in three-point flexure experiments (Fig. 5b).

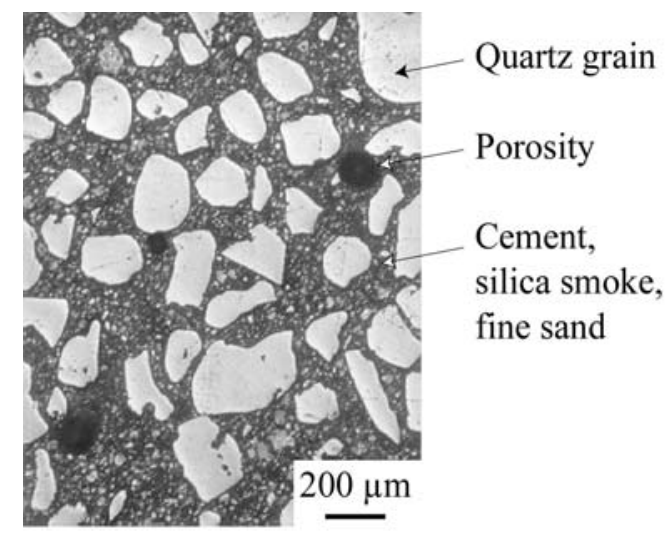

$-a-$

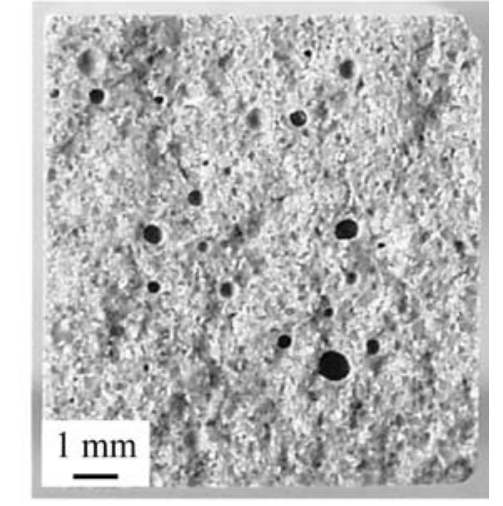

$-b-$

Figure 5. a-Microstructure of the high performance concrete studied herein. b-Fractured surface after a three-point flexural test.

As expected, the behavior is elastic-brittle and the failure stress is scattered. Figure 6 shows the corresponding Weibull plot for 18 experiments on samples of size $11.2 \times 10.2 \times 150 \mathrm{~mm}^{3}$ submitted to three-point flexure (outer span: $130 \mathrm{~mm}$ ). A Weibull modulus of 9.5 is obtained and $\sigma_{0}=23 \mathrm{MPa}$ when $1 / \lambda_{0}=59 \mathrm{~mm}^{3}$ (i.e., identical to the effective volume). To compare the three geomaterials studied so far, Table 1 summarizes the Weibull parameters for the same reference density $1 / \lambda_{0}=1 \mathrm{~cm}^{3}$. 


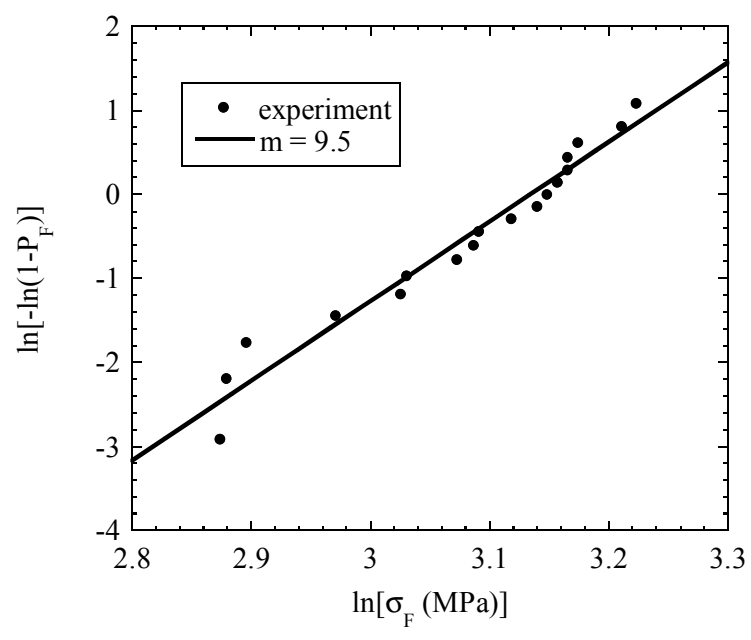

Figure 6. Weibull plot for a high performance concrete in a series of three-point flexural tests. Best fit with a Weibull model $(m \approx 9.5)$.

Table 1. Weibull parameters $\left(m, \sigma_{0}\right)$ for three geomaterials compared with a silicon carbide ceramic and glass when $1 / \lambda_{0}=1 \mathrm{~cm}^{3}$. Average strength $\left(\sigma_{a v}\right)$ for an effective volume equal to $1 \mathrm{dm}^{3}$.

\begin{tabular}{|c|c|c|c|}
\hline Material & $m$ & $\sigma_{0}(\mathrm{MPa})$ & $\sigma_{a v}(\mathrm{MPa})$ \\
\hline limestone & 3 & 10.5 & 1 \\
\hline microconcrete $^{\circ}$ & 7.3 & 6.0 & 2.2 \\
\hline DUCTAL $^{\circledR}$ & 9.5 & 17.1 & 7.8 \\
\hline $\mathrm{SiC}^{\dagger}$ & 9.6 & 180 & 83 \\
\hline sodalime glass $^{\ddagger}$ & 28.5 & 1330 & 1020 \\
\hline
\end{tabular}

${ }^{\dagger}$ after Denoual and Riou (1995), "bulk defects [after Gy and Guillemet (1992)].

It is worth noting that all the geomaterials have scale parameters less than those observed in ceramics and glasses. As expected, the high performance concrete studied herein has properties significantly better than those of other geomaterials. 


\subsection{Third case study: ferrocement}

Ferciment (i.e., "ferrocement") was invented 150 years ago by Lambot who, in 1845 constructed pots and seats, and built a boat with this material in 1848. A first patent on the mixed use of iron and cement was made in 1851 and ferciment is patented since 1855 (Lambot, 1855; Marrey, 1995). Its utilization for structural purposes only started in 1943 thanks to Nervi's contributions (1951). Ferrocement is the oldest form of reinforced concrete and is composed of a cement-based mortar or concrete matrix reinforced with a mesh of closely spaced iron rods or wires (Naaman, 2000). Nowadays many civil engineering applications use some kind of fiber-reinforced concrete or cement (Balaguru et al., 1992). The interest in these materials is due to the gain in toughness and ductility in the presence of cracks that are bridged by the fibers. Furthermore, microconcrete reinforced by fibers ( $\mu \mathrm{CoReF})$ has been developed as a low-cost material to be used in thin-walled structural components [e.g., pre-formed skeleton (El Debs, 2000)]. The strength and deformability of these structures are improved when compared to conventional "ferrocement" composites (Hanai et al., 1994). The prediction of cracking in such structural components is essential for design purposes and this constitutes the main goal of the present case study.
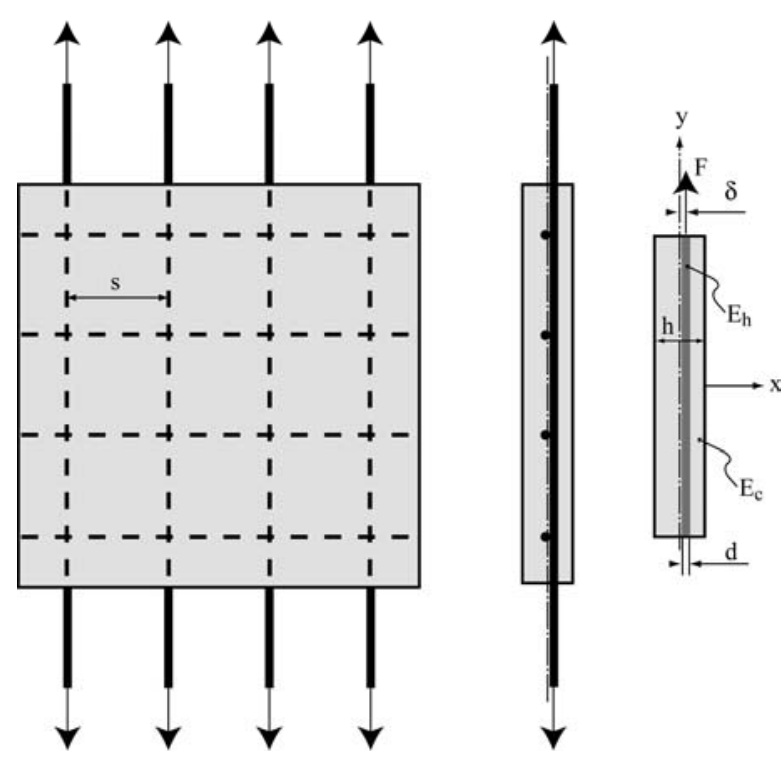

Figure 7. Panel geometry $\left(400 \times 400 \times 25 \mathrm{~mm}^{3}, S=100 \mathrm{~mm}\right)$ and $300 \mathrm{~mm}$ long beam model used to account for the eccentricity $\delta$. 
The reinforcements are wires $3.8 \mathrm{~mm}$ in diameter made of low carbon steel. The average tensile strength is of the order of $870 \mathrm{MPa}$ with an average Young's modulus of $210 \mathrm{GPa}$. For a frame made of a perpendicular array of 8 welded wires (spacing between wires: $S=100 \mathrm{~mm}$, wire diameter: $d=3.8 \mathrm{~mm}$ ), the ultimate strength is given equal to $895 \mathrm{MPa}$ in the longitudinal direction, and $870 \mathrm{MPa}$ in the transverse direction. In the present case, one set of 33 panels is analyzed (panel size: $400 \times 400 \times 25 \mathrm{~mm}^{3}$ ). The matrix is identical to that studied in Section 2.6. The reinforcement consists of a grid of welded steel wires. Figure 7 shows a schematic view of the sample geometry. Following the analysis initially proposed by Aveston et al. (1971; 1973), let us consider an elementary cell consisting of a continuous fiber (Young's modulus $E_{S}$ and volume fraction $f$ ) embedded in a matrix (Young's modulus $E_{c}$ and volume fraction 1-f). A perfectly bonded interface is assumed so that the longitudinal strains are identical in the matrix and in the fiber (Fig. 8).

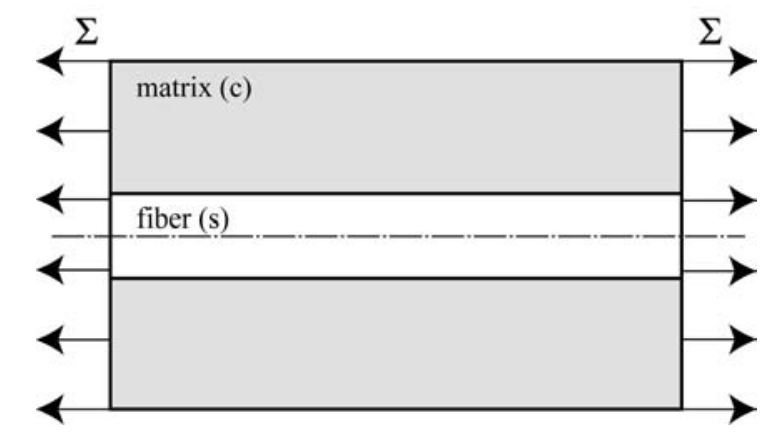

Figure 8. Elementary cell used in the analysis of single and multiple cracking regimes.

The applied stresses are assumed to be uniaxial and uniform in each section. When no cracking occurs, the macroscopic Young's modulus is assumed to be equal to

$$
E=(1-f) E_{c}+f E_{s},
$$

so that the stress in the fiber is expressed as

$$
\sigma_{s}=\Sigma \frac{E_{s}}{E},
$$

and that in the matrix as 
14 Nom de la revue. Volume $\mathrm{X}-\mathrm{n}^{\circ} \mathrm{X} / 2002$

$$
\sigma_{c}=\Sigma \frac{E_{c}}{E} .
$$

Hence, the applied stress $\Sigma$ is related to $\sigma_{s}$ and $\sigma_{c}$ by

$$
f \sigma_{s}+(1-f) \sigma_{c}=\Sigma .
$$

The microconcrete matrix is weaker than the reinforcement. Multiple matrixcracking will occur when the first matrix crack does not lead to the failure of the fiber bridging the crack. If the strength $f \sigma_{s u}$ is less than the stress level at which matrix-cracking occurs $\Sigma_{c r}=\sigma_{c u} E / E_{c}$, there will be single matrix-cracking. Conversely, when

$$
f>f_{c r}=\left(\frac{\sigma_{s u}}{\sigma_{c u}}+1-\frac{E_{s}}{E_{c}}\right)^{-1},
$$

there will be multiple matrix-cracking. To obtain the previous results, the failure strengths of the matrix and the fibers were assumed to be deterministic. In practice, this hypothesis is only a simplification. In the present case, only the matrix strength is considered to be of random nature. Let us associate to each failure stress of the matrix $\sigma_{c u}$ a cracking probability $P_{c r}$ that can be described by a two-parameter Weibull model [see Eq. (6) with $Z_{\text {eff }}=V_{c}$ ]

$$
\sigma_{c u}\left(P_{c r}\right)=\sigma_{0}\left(\lambda_{0} V_{c}\right)^{-1 / m}\left[-\ln \left(1-P_{c r}\right)\right]^{1 / m},
$$

so that the critical volume fraction is defined in terms of the first matrix-cracking event in the composite

$$
f_{c r}\left(P_{c r}\right)=\left(\frac{\sigma_{s u}}{\sigma_{0}\left(\lambda_{0} V_{c}\right)^{-1 / m}\left[-\ln \left(1-P_{c r}\right)\right]^{1 / m}}+1-\frac{E_{S}}{E_{c}}\right)^{-1} .
$$

For instance, for a fiber volume fraction $f=0.005$, multiple matrix-cracking is likely to occur (i.e., $f>f_{c r}$ ) for a probability $P_{c r}$ of $72 \%$ when the volume of the matrix is equal to the reference volume (i.e., $\lambda_{0} V_{c}=1$ ). Furthermore, the higher the volume $V_{c}$, the lower the failure stress for the same failure probability (i.e., $\mathrm{V}$ effect), therefore the more likely multiple matrix-cracking. This result is valid provided the composite is subjected to a macroscopic tensile stress. If the stress field is heterogeneous, the above-mentioned conclusion can be utilized by considering the effective volume $V_{c} H_{m}$ instead of the volume $V_{c}$ (i.e., $\mathrm{H}$ Effect) as will be shown below. 
In practice, the steel grid induces a loss of symmetry of the microconcrete panels because of the eccentricity $\delta$ (see Fig. 9). Consequently, the previous analysis has to be adapted to account for flexure coupled with tension. A FE analysis shows that the top part and left part of the modeled quarter sample are not significantly loaded compared to the center because of the way the strains are prescribed by the transverse wires (Silva, 2002). Hence, the loaded volume for the prediction of the first cracking stress is equal to $300 \times 300 \times 25 \mathrm{~mm}^{3}$. To described flexure coupled with tension, the longitudinal strain field is given by

$$
\alpha \varepsilon_{\max } \leq \varepsilon_{y y}(x)=\left[\frac{1+\alpha}{2}+(1-\alpha) \frac{x}{h}\right] \varepsilon_{\max } \leq \varepsilon_{\max } \text { when }-h / 2 \leq x \leq h / 2 .
$$

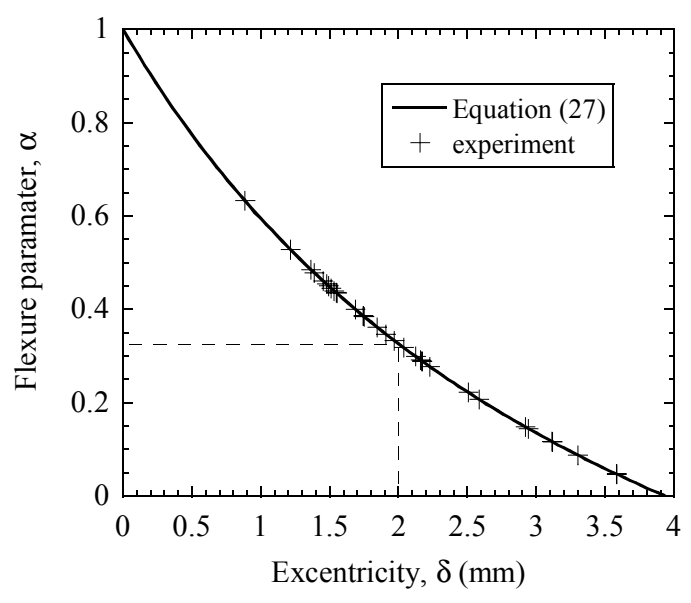

Figure 9. Flexure parameter $\alpha$ vs. eccentricity $\delta$. The crosses are experimental data. The experimental average $\bar{\alpha}=0.33$ corresponds to an eccentricity $\delta=2 \mathrm{~mm}$.

Because the eccentricity $\delta$ is very difficult to control, a beam calculation is used to relate $\delta$ to the flexure parameter $\alpha$. The wires aligned along the $z$ direction are not modeled. However, it is assumed that thanks to their presence, Eq. (24) constitutes a good approximation of the longitudinal strain field in an equivalent beam for which the elastic behavior in the $z$ direction is homogenized for $\delta-d / 2 \leq x \leq \delta+h / 2$. The equivalent Young's modulus in this homogenized region is computed as

$$
E_{h}=\left(1-f_{h}\right) E_{c}+f_{h} E_{s},
$$


where the apparent surface fraction of fibers is computed as

$$
f_{h}=2\left(\frac{\pi d^{2}}{4}\right) \frac{1}{2 S d}=\pi d / 4 S
$$

The eccentricity $\delta$ induces a flexural moment $\delta F$ (Fig. 8) leading to the following relationship between $\delta$ and $\alpha$

$$
\alpha=\frac{\left[\frac{1}{12}\left(h^{2}-\frac{d^{3}}{h}\right)-\frac{\delta}{2}(h-d)\right] E_{m}+\left(\frac{d^{3}}{12 h}-\frac{d \delta}{2}\right) E_{h}}{\left[\frac{1}{12}\left(h^{2}-\frac{d^{3}}{h}\right)+\frac{\delta}{2}(h-d)\right] E_{m}+\left(\frac{d^{3}}{12 h}+\frac{d \delta}{2}\right) E_{h}}
$$

One can evaluate a priori the effective volume in a 'tensile' test of the panels. By using Eqs. (9) and (24) and neglecting the fiber stress contribution (since $f$ is very small), the following stress heterogeneity factor is found

$$
H_{m}(\alpha)= \begin{cases}\frac{1-\alpha^{\mathrm{m}+1}}{(m+1)(1-\alpha)} & \text { when } \alpha \geq 0 \\ \frac{1}{(m+1)(1-\alpha)} & \text { otherwise }\end{cases}
$$

Equation (28) shows that the lower $\alpha$, the lower the stress heterogeneity factor and the higher the average failure stress [see Eqn. (11)]. By assuming that the relevant volume to consider is $V_{c}=300 \times 300 \times 25 \mathrm{~mm}^{3}$, the dimensionless effective volume $\lambda_{0} V_{c} H_{m}$ is of the order of 20 and a multiple cracking regime is to be expected.

Each of the 33 panels that have been tested exhibits a different value of $\alpha$ for the cracking events. In Fig. 9, the values of $\alpha$ corresponding to the first matrix crack are plotted and the eccentricities deduced from Eq. (27). As anticipated, these values are scattered. Yet the range of values allows us to conclude that the samples did not experience compressive stresses since $\alpha$ remains positive. The mean value of $\alpha$ is equal to 0.33 and that of the eccentricity $\delta$ is of the order of $2 \mathrm{~mm}$ (corresponding standard deviation: $0.7 \mathrm{~mm}$ ). This value can be compared to the value $\delta=1.9 \mathrm{~mm}$ (i.e., $\delta=h / 2$ ) that corresponds to a perfect positioning of the steel frame in the mid-plane of the panel. These results show that, even though a millimeter positioning was achieved, it is not sufficient to consider one single value 
for $\alpha$. Since each experiment has a different value of $\alpha$, the only way to treat globally the scatter is to resort to the Weibull stress [Eq. (16)] so that all data can be compared with one another.

Figure 10 summarizes all the experimental observations in the modified Weibull plot (i.e., $\ln \left[-\ln \left(1-P_{F}\right)\right]$ vs. $\left.\ln \sigma_{w}\right)$. All experimental data are located above the curve given by the Weibull model identified with the flexure experiments. It therefore constitutes a lower estimate. This can be shown when fitting the experimental data with the same Weibull modulus (i.e., $m=7.3$ ) and leaving the scale parameter free.

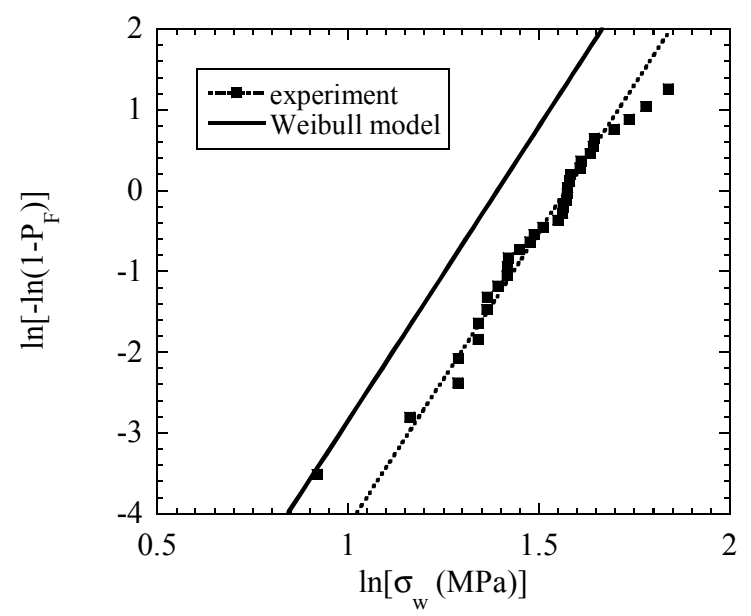

Figure 10. Modified Weibull plot corresponding to the first, second and third cracking stresses. The solid line corresponds to the Weibull parameters determined from the flexure data. The dashed line corresponds to the Weibull scale parameter determined by using the present data.

A value $\hat{\sigma}_{0}=4.8 \mathrm{MPa}$ is found for the same reference density (i.e., $1 / \lambda_{0}=20 \mathrm{~cm}^{3}$ ) with a correlation coefficient equal to 0.96 . It can be noted that the average effective volume observed in the experiments prior to first cracking, $V_{\text {eff }} \approx 240 \mathrm{~cm}^{3}$, is at least two orders of magnitude larger than those that correspond to the unreinforced beams tested in flexure. Consequently, an extrapolation of the 
model to these very different scales may explain the $20 \%$ difference in scale parameter.

\section{Dynamic fragmentation of geomaterials}

\subsection{Experimental evidence}

Tensile cracking, one of the major degradation mechanisms, can be observed during impact by using so-called Edge-On Impact (EOI) configurations instead of a real configuration where the degradation is 'hidden' in the bulk of the ceramic. These configurations are developed by the Ernst-Mach-Institute (EMI) in Germany (Hornemann et al., 1984; Strassburger et al., 1994) and more recently by the Centre Technique d'Arcueil (CTA) in France (Denoual et al., 1998a; Riou et al., 1998). It can be shown that the same damage mechanism (i.e., damage in tension) is observed in EOI and in real impact configurations (Denoual et al., 1996).

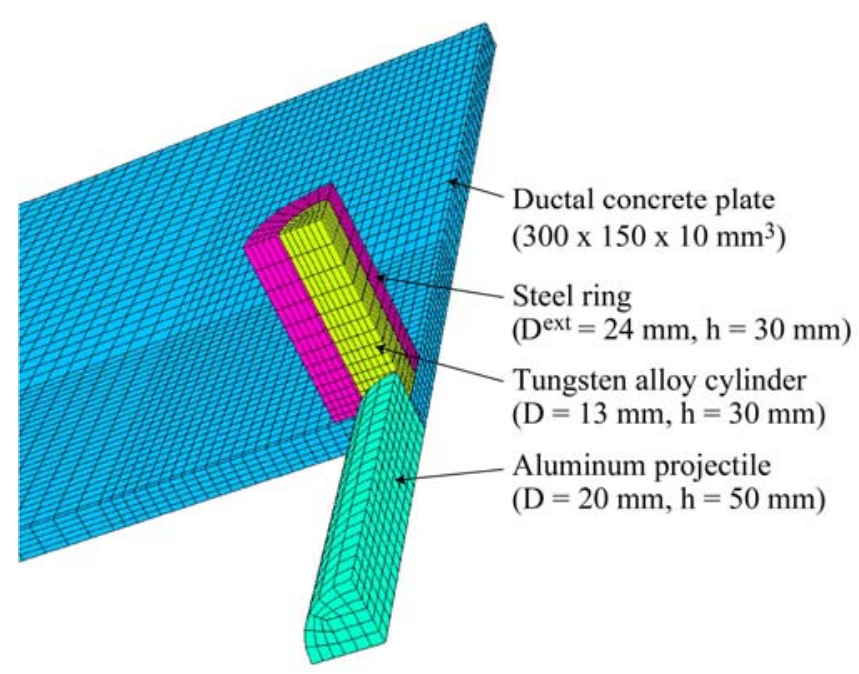

Figure 11. One quarter of an edge-on impact configuration with dynamic confinement.

To avoid confined damage induced by the compressive wave close to the impact zone, a special EOI setup is used (Fig. 11). It consists in creating an additional dynamic confinement obtained by using a steel ring containing a tungsten cylinder whose radius is greater than that of the projectile. This system creates an additional 
confinement during $13 \mu \mathrm{s}$ that prevents damage to develop in these zones by reducing the deviatoric stress (i.e., less than $240 \mathrm{MPa}$ for a distance greater than $12 \mathrm{~mm}$ from the impact point) to levels below the threshold of damage under confined conditions (i.e., of the order of $400 \mathrm{MPa}$ ). When using a 2024 aluminum alloy projectile, this setup allows to analyze fragmentation with no prior confined damage (i.e., hoop stresses greater than $35 \mathrm{MPa}$ for a distance less than $80 \mathrm{~mm}$ from the impact point). Figure 12 shows a post-mortem observation when the tile is put in a sarcophagus to prevent the fragments to move too much. In this configuration, a blunt projectile ( $20 \mathrm{~mm}$ in diameter and $50 \mathrm{~mm}$ in length) impacts at $88 \mathrm{~m} / \mathrm{s}$ a concrete plate of size $300 \times 150 \times 10 \mathrm{~mm}^{3}$. After impact, the tile is coated in an epoxy resin and polished for macroscopic (and microscopic) analyses.

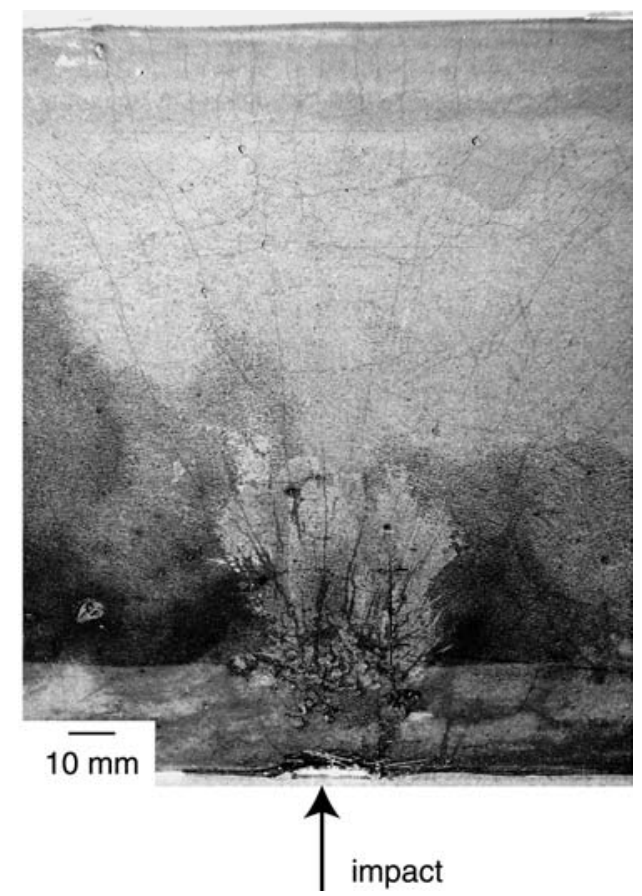

Figure 12. Post-mortem view of an impacted high performance concrete tile by an aluminum projectile with a confined configuration.

It is worth remembering that the same principle has been used to devise the experiments on rocks, for which an edge-on-blast configuration was developed and validated (Fig. 2). In that case, only post-mortem observations could be performed. 


\subsection{Fragmentation model}

When a dynamic fracture is initiated in mode I, the local stress state is modified around the crack by a stress relief wave which is a complex function of time, crack velocity and stress wave celerity. To understand why a crack nucleates, one has to model the interaction of the zone (i.e., volume, surface or length) affected by the stress relief and other defects that would nucleate. The behavior of a flaw around a nucleated crack can be described by two different cases:

- the flaw is far from the nucleated one and the microscopic stress state is not affected,

- the flaw is in the interaction zone and the microscopic tensile stress is decreasing, i.e., no cracks are emanating from this potential initiation site.

A third case may occur in which the flaw is in the affected zone but the local tensile stress increases, i.e., initiation may occur. It is assumed that this case is insignificant in this problem.

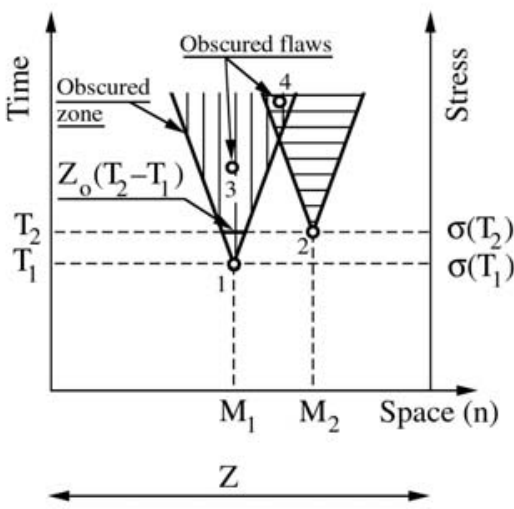

Figure 13. Fragmentation and obscuration phenomena.

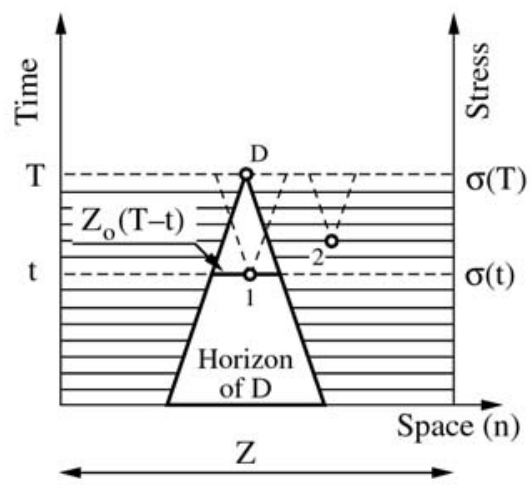

Figure 14. Schematic of the horizon of a defect $D$.

The direction of the microscopic maximum principal stress is assumed to be constant (i.e., proportional loadings), which allows one to use $\sigma=\left(\sigma_{1}, \sigma_{2}, \sigma_{3}\right)$ instead of the stress tensor as an equivalent failure stress. The crack nucleation can be represented on a space-time graph (Fig. 13). The space location of the defects is represented in a simple abscissa (instead of a three-, two- or one-dimensional representation) of an $\mathrm{x}-\mathrm{y}$ graph where the $\mathrm{y}$-axis represents the time (or stress) to failure of a given defect. The first crack nucleation occurs at time $T_{1}$ (corresponding 
to a stress $\left.\sigma\left(T_{1}\right)\right)$ at the space location $\mathrm{M}_{1}$ and produces an 'obscured zone' $Z_{\mathrm{o}}\left(T-T_{1}\right)$ increasing with time. At time $T_{2}$ (corresponding to a stress $\sigma\left(T_{2}\right)>\sigma\left(T_{1}\right)$ ) a second crack nucleates in a non-affected zone and produces its own obscured zone. The third and fourth defects do not nucleate because they are obscured by the first and both first and second cracks, respectively.

It is worth noting that the stress levels in overlapping obscured zones cannot be greater than the highest initiation stress associated to the considered obscured zones. The space-time graph is composed of the union of obscured zones in which no flaws can initiate and the complementary zone in which cracks can nucleate. Because different obscured zones may overlap (i.e., a flaw can be obscured by one or more other cracks), it is preferable to define the conditions of non-obscuration for a given defect by examining the inverse problem. It consists in considering the past history of a defect that would break at a time $T$. The defect will break if no cracks exist in its horizon. For a given flaw D its horizon is defined as a space-time zone in which a crack will always obscure D (Fig. 14). Outside the horizon, a crack will never obscure D. The flaw distribution can be split into two parts and the average density of cracks can be written as

$$
\lambda_{b}(\sigma)=\lambda_{t}(\sigma)-\lambda_{o b s}(\sigma)
$$

where $Z \lambda_{t}(\sigma)$ denotes the mean number of flaws that may break in a zone of measure $Z$ (i.e., volume $(n=3)$, surface $(n=2)$ or length $(n=1))$ for a stress less than or equal to $\sigma$. The subscripts indicate the crack density (b), the obscured flaw (obs), and the total density of flaws able to break (t). Furthermore, we assume that the distribution of total flaws is modeled by a Poisson point process of intensity $\lambda_{t}$ (see Section 1). New cracks will initiate only if the defect exists in the considered zone and if no cracks exist in its horizon so that (Denoual et al., 1997)

$$
\frac{d \lambda_{b}}{d t}(T)=\frac{d \lambda_{t}}{d t}(T)\left[1-P_{o}(T)\right] \text { with } \lambda_{b}(0)=0
$$

where $1-P_{O}$ is the probability that no cracks exist in the horizon. The variable $1-P_{o}$ can be split into an infinity of events defined by the probability of finding at $t$ a new crack during a time step $d t$ in an obscuration zone $\Omega_{o}(T-t)$. This probability increment is written by using a Poisson point process of intensity $d \lambda_{t} / d t$. Those independent events can be used to provide an expression for $P_{o}$ 


$$
P_{o}(T)=1-\exp \left(-\int_{0}^{T} \frac{d \lambda_{t}}{d t}(t) Z_{o}(T-t) d t\right)
$$

where $Z_{o}(T-t)$ is the measure of the obscuration zone at $T$ for a defect that would break at $t$. At the beginning of loading, no interactions occur and $\lambda_{b}(T) \approx \lambda_{t}(T)$ and as more and more cracks nucleate $\lambda_{b}(T) \ll \lambda_{t}(T)$. It is expected that the crack density saturates when $T \rightarrow+\infty$ even though the total density of flaws able to break may approach infinity. Usually, the obscuration zone cannot be assumed as a timeconstant variable and since no analytical expressions are available for $Z_{o}(T-t)$, an approximation will be proposed. The shape of the interaction zone is supposed to be constant, i.e., all the interaction zones are self-similar (Bluhm, 1969; Freund, 1972) and $Z_{o}(T-t)$ can be written as

$$
\left.Z_{o}(T-t)=S[k C(T-t))\right]^{n}
$$

where $S$ is a shape parameter, $k \in] 0,1]$ is a constant, $C$ the longitudinal stress wave velocity so that $k C(T-t)$ is a representative length of the relaxation around a crack.

When dynamic loadings are considered with a constant stress rate $\dot{\sigma}$ one can define a dimensionless flaw density $\left(\tilde{\lambda}=\lambda / \lambda_{c}\right)$, time $\left(\widetilde{T}=T / t_{c}\right)$, space measure $\left(\widetilde{Z}=Z / Z_{c}\right)$ and stress $\left(\tilde{\sigma}=\sigma / \sigma_{c}\right)$ from the condition

$$
\begin{gathered}
\lambda_{c} Z_{c}=1 \text { with } \lambda_{c}=\lambda_{c}\left(t_{c}\right) \text { and } Z_{c}=Z_{o}\left(t_{c}\right) \\
t_{c}=\left(\frac{\sigma_{0}^{m}}{\lambda_{0} \dot{\sigma}^{m} S(k C)^{n}}\right)^{1 / m+n}, Z_{c}=\left(\frac{\sigma_{0}(k C) S^{1 / n}}{\lambda_{0}^{1 / m} \dot{\sigma}}\right)^{m n / m+n}
\end{gathered}
$$

where the subscript $c$ denotes characteristic quantities. A characteristic stress can be defined by $\sigma_{c}=\dot{\sigma}_{c}$. Equation (33) expresses the fact that the characteristic zone of measure $Z_{c}$ contains a unique flaw that may break at the characteristic time $t_{c}$. By using Eqs. (1), (31) and (32) an analytical solution is given for the differential equation (30) in the case of a constant stress rate $\dot{\sigma}$

$$
\tilde{\lambda}_{b}(\widetilde{T})=\frac{m}{m+n}\left[\frac{(m+n) !}{m ! n !}\right]^{\frac{m}{m+n}} \gamma\left(\frac{m}{m+n}, \frac{m ! n !}{(m+n) !} \widetilde{T}^{m+n}\right)
$$


where $\gamma$ is the incomplete gamma function. Figure 15 shows the saturation phenomenon as the considered time becomes greater than the characteristic time. The crack density at saturation $\widetilde{\lambda}_{b}(\infty)$ can be derived from Eq. (34) and is only dependent on the Weibull modulus $m$ and the space dimension $n$ when normalized by $\lambda_{c}$. Figure 16 shows an increase of the number of cracks at saturation with the Weibull modulus $m$. An explanation to this phenomenon can be proposed by using Eq. (30). With a high Weibull modulus $m$, the density of cracks will increase sharply in a small time step when the time $T$ becomes greater than $t_{c}$. Because of the time dependence of the saturation mechanism, many cracks nucleate before any significant saturation and the material will be fully fragmented. If $m$ is small, there is much more time between two crack initiations. The first nucleated cracks can then obscure other defects before their own nucleation and only few defects eventually nucleate.
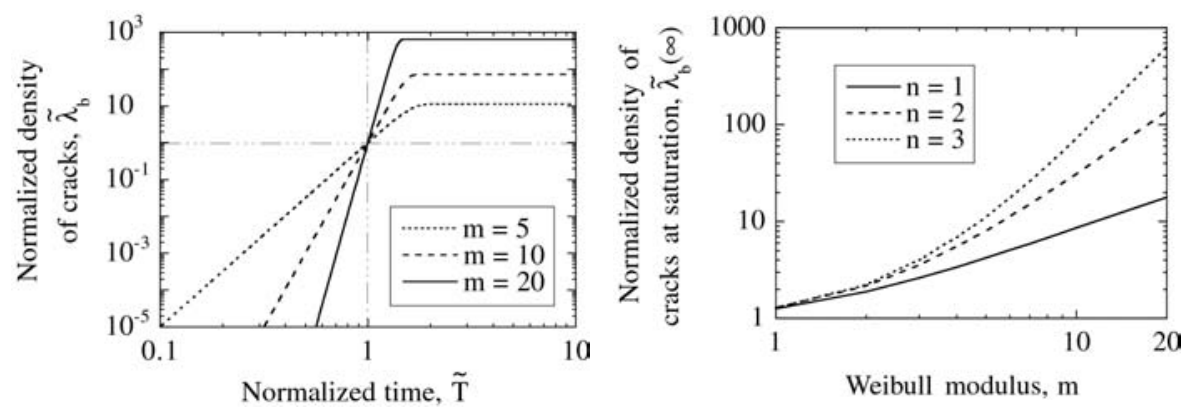

Figure 15. Normalized density of Figure 16. Normalized density of cracks vs. normalized time for three cracks at saturation vs. Weibull different Weibull moduli $m$. modulus for different values of the space dimension $n$.

\subsection{Damage model}

The variable $P_{o}$ can be used to define a damage variable in the framework of Continuum Damage Mechanics, even if $P_{o}$ describes a non-homogeneous stressfield due to the randomness of fragmentation (Denoual et al., 2000). By averaging over a representative zone (to be specified later on), $P_{o}$ is equal to the damage variable $D$, with $D=0$ for the virgin material and $D=1$ for the fully broken one. It is interesting to notice that the first order approximation of Eq. (30) leads to the differential equation proposed by Grady and Kipp (1980) to describe the evolution 
of a damage variable. By using Eqs. (30) and (31), the kinetic law of the damage variable $D$ can be written as

$$
\frac{d^{n-1}}{d t^{n-1}}\left(\frac{1}{1-D} \frac{d D}{d t}\right)=\lambda_{t}[\sigma(t)] n ! S(k C)^{n}
$$

An expression for the damage parameter $D$ can be derived by integrating Eq. (35) for a constant stress rate $\dot{\sigma}$

$$
D=1-\exp \left(-\frac{m ! n !}{(m+n) !} \widetilde{T}^{m+n}\right) .
$$

Equation (36) shows that $D(\widetilde{T}=1) \approx 0$ and $D(\widetilde{T}=2) \approx 1$ (i.e., most of the damage change occurs during a time interval equal to the characteristic time $t_{c}$. During $t_{c}$, the measure of the horizon is limited by $Z_{c}$ so that the minimum measure of the representative zone is $Z_{c}$. By noting that the applied stress $\bar{\sigma}$ is related to the local (or effective) stress $\sigma$ by $\sigma=\bar{\sigma} /(1-D)$, the ultimate strength $(d \bar{\sigma} / d \sigma=0)$ is denoted by $\bar{\sigma}_{\text {max }}$ and is expressed as

$$
\frac{\bar{\sigma}_{\max }}{\sigma_{c}}=\left(\frac{(m+n-1) !}{\mathrm{e} m ! n !}\right)^{1 / m+n}
$$

The normalized ultimate strength only depends upon the Weibull parameter $m$ and the space dimension $n$. The ultimate strength $\bar{\sigma}_{\max }$ is then proportional to $\dot{\sigma}^{n /(m+n)}$. This result is in agreement with experimental data of oil shale (Grady et al., 1980) and microconcrete (Brara et al., 2001; Hild et al., 2003)

\subsection{Discrete vs. continuum approach, probabilistic vs. deterministic description}

Different failure regimes are observed. Under quasi-static loading conditions, a weakest link hypothesis is made (Section 2). It follows that the first fracture event leads to the complete failure of a structure made of brittle materials. Conversely, under dynamic loading conditions, multiple fragmentation is observed and a damage model can be derived (Section 3.3). The aim of the present section is to get the conditions of applications of the previous results. Figure 17 shows the change of the tensile strength with the stress rate for an effective volume $V_{\text {eff }}(n=3)$ equal to $1 / \lambda_{0}$. The lines represent analytical solutions while the dots and error bars are Monte-Carlo simulations (500 realizations per point). For a dimensionless stress 
rate less than 0.5 , the ultimate strength is not modified by the loading rate and follows a classical Weibull model [see Eqn. (11)]. When $\dot{\sigma}$ increases by approximately one order of magnitude, the ultimate strength follows the analytical solution (37). During the transition, the difference between the dashed lines [given by Eqs. (37) and (11)] and simulations does not exceed $10 \%$. The standard deviation significantly decreases in the multiple fragmentation regime. Even if the ultimate strength has to be defined for static and dynamic loadings by a mean and a standard deviation, one can see that dynamic loadings lead to a more 'deterministic' behavior.

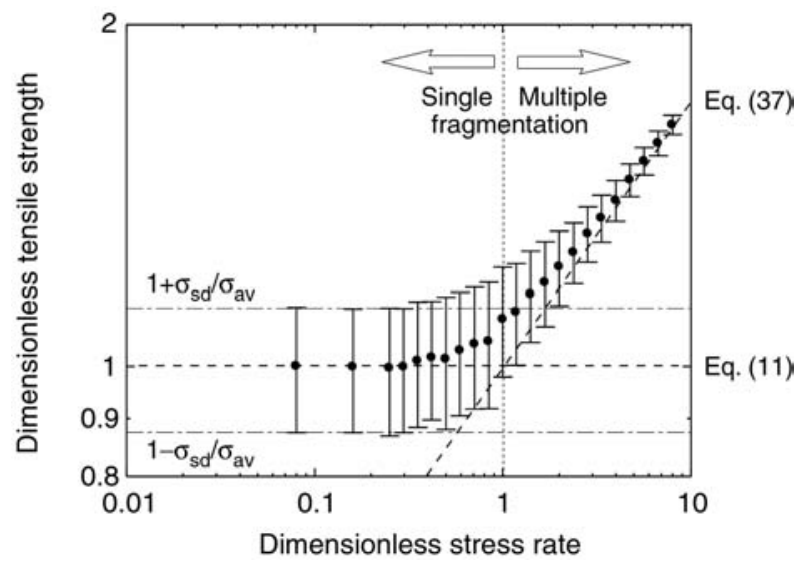

Figure 17. Normalized tensile strength $\sigma_{t s} / \sigma_{a v}$ vs. normalized stress rate $\dot{\sigma} / \dot{\sigma}_{t}$ when $m=10$. Solid circles (average) and bars (standard deviates) are given by the Monte-Carlo simulations (500 realizations for each point).

The transition between single and multiple fragmentation can be estimated by the following condition (Denoual et al., 1998b)

$$
\sigma_{a v}=\bar{\sigma}_{\max }(\dot{\sigma})
$$

The transition between quasi-static and dynamic descriptions defined by Eq. (38) leads to the following inequalities

$$
\dot{\sigma} \begin{cases}<\dot{\sigma}_{t} & \text { single fragmentation } \\ \geq \dot{\sigma}_{t} & \text { multiple fragmentation }\end{cases}
$$

with the transition stress rate $\dot{\sigma}_{t}$ defined by 


$$
\dot{\sigma}_{t}=\sigma_{0} k C\left(\lambda_{0} S\right)^{1 / n}\left(Z_{\text {eff }} \lambda_{0}\right)^{(m+n) / m n}\left(\frac{\mathrm{e} n ! m !}{(m+n-1) !} \Gamma^{m+n}\left(\frac{m+1}{m}\right)\right)^{1 / n} .
$$

This transition does not only depend on material parameters but also involves the measure $Z_{\text {eff }}$ of the considered element. The response of a large structure can be considered as 'dynamic' for low stress rates even if the material follows a weakest link hypothesis for the same loading applied on a smaller volume.

For each principal stress direction $\underline{d}_{i}$, an anisotropic damage variable $D_{i}$ is defined so that the principle strains $\bar{\varepsilon}_{i}$ are related to the principal stresses $\bar{\sigma}_{i}$ by

$$
\bar{\varepsilon}_{i}=\bar{K}_{i j}\left(D_{1}, D_{2}, D_{3}\right) \bar{\sigma}_{j}
$$

where the usual index summation is used. The compliance tensor $\bar{K}$ is defined by

$$
\underline{\underline{K}}\left(D_{1}, D_{2}, D_{3}\right)=\frac{1}{E}\left(\begin{array}{ccc}
\frac{1}{1-D_{1}} & -v & -v \\
-v & \frac{1}{1-D_{2}} & -v \\
-v & -v & \frac{1}{1-D_{3}}
\end{array}\right)_{\left(\underline{d}_{1}, \underline{d}_{2}, \underline{d}_{3}\right)}
$$

where $E$ is the Young's modulus and $v$ the Poisson's ratio of the undamaged material. In $3 \mathrm{D}$ configurations $(n=3)$, the kinetic law for $D_{i}$ is expressed in a differential form [see Eq. (35)]

$$
\frac{d^{2}}{d t^{2}}\left(\frac{1}{1-D_{i}} \frac{d D_{i}}{d t}\right)=6 \hat{\lambda}_{t}\left(\sigma_{i}\right) S(k C)^{3}
$$

when $\sigma_{i}>0$ and $\dot{\sigma}_{i}>0$ (the effective principal stress $\sigma_{i}$ is related to the macroscopic principal stress $\bar{\sigma}_{i}$ by $\left.\bar{K}_{i j}\left(D_{1}, D_{2}, D_{3}\right) \bar{\sigma}_{j}=\bar{K}_{i j}(0,0,0) \sigma_{j}\right)$. The defect density $\hat{\lambda}_{t}$ associated with the Weibull model is defined so that the damage model is used only if at least one defect is broken in the considered finite element $\Omega_{F E}$ of volume $V_{F E}$ (Denoual et al., 2002)

$$
V_{F E} \hat{\lambda}_{t}\left(\sigma_{i}\right)=\left\{\begin{array}{cc}
0 & \text { if } \sigma_{i}<\sigma_{k} \\
\max \left[V_{F E} \lambda_{0}\left(\frac{\sigma_{i}}{\sigma_{0}}\right)^{m}, 1\right] & \text { otherwise }
\end{array}\right.
$$


where $\sigma_{k}$ a random failure stress obeying the Weibull law (1). For low stress rates, the first defect breaks and relaxes the stresses in $\Omega_{F E}$. It follows that the quasistatic Weibull properties [Eqs. (11) and (12)] are recovered. For a high (tensile) stress rate, the zone relaxed by the first defect to break has a weak influence and a deterministic (damage) approach applies. The behavior of a FE cell is therefore not deterministic and numerous calculations have to be performed when average values are awaited [e.g., average macroscopic ultimate stress $\left.\bar{\sigma}_{\max }(\dot{\sigma})\right]$.

\subsection{Fourth case study: dynamic fragmentation of high-performance concrete}

In the following, the capability of the damage model is evaluated to reproduce observed degradation patterns. The velocity of a single crack is estimated to be about $1875 \mathrm{~m} / \mathrm{s}$ (i.e., the value of the parameter $k$ is equal to 0.4 ). The simulation is performed on the confined EOI configuration with an impact velocity of $88 \mathrm{~m} / \mathrm{s}$. The random stress to failure is computed by using Eq. (1) for a FE volume of $1 \mathrm{~mm}^{3}$.

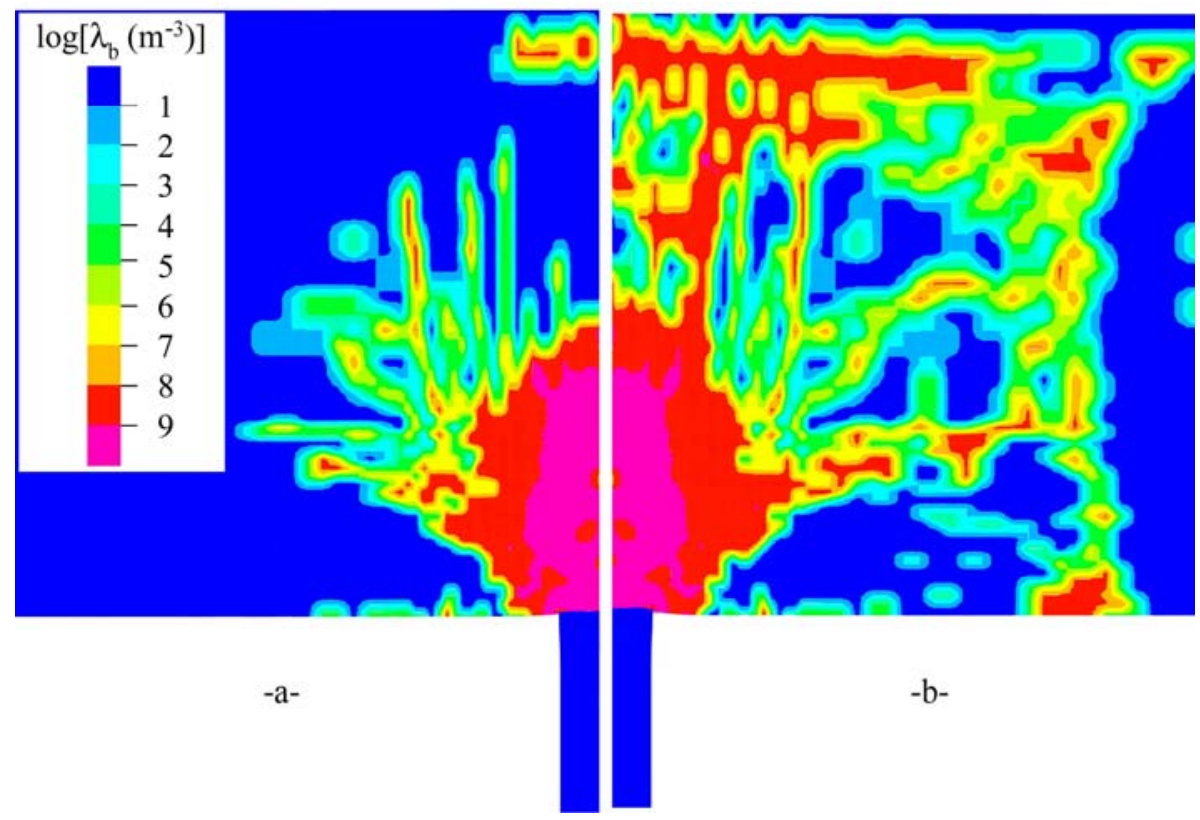

Figure 18. Contour of crack density associated to the first principal direction $35 \mu s(a)$ and $50 \mu s$ (b) after impact in a confined EOI experiment on Ductal ${ }^{\mathbb{R}}$. 
Figure 18 shows the crack density associated to the first principal stress direction at the end of the fragmentation process. For high stress rates (i.e., in front of the projectile and in the Hertz-like cone crack), many cracks nucleate in a FE cell. Failure of an element set, which can be compared to macroscopic cracks, can be observed in addition to the continuous degradation generated close to the impact zone. However, there are some difficulties in handling macroscopic cracks. When a crack is created, there is a tendency to follow the direction of the FE mesh. This result may be improved by refining the mesh and the model (Brajer et al., 2002). Overall, the prediction is in reasonable agreement with the experimental observations (Fig. 12), namely, a fine fragmentation in the first part of the plate followed by long radial cracks in the second half.

\section{Summary}

A probabilistic (Weibull) model was used in different situations discussed herein. First, a weakest link hypothesis was made. Under this assumption, a single (discrete) event leads to the complete failure of a structure. Then multiple cracking was discussed. A deterministic formulation can be used within the framework of CDM, provided there are numerous local events occurring almost simultaneously. However, strain-softening may lead to strain localization (i.e., macrocrack initiation) which is a discrete phenomenon again. Some solutions have been proposed, viz. non-local damage models (Brajer et al., 2002) or discrete models (Camacho et al., 1996; Mastilovic et al., 1999).

\section{Acknowledgements}

The author wishes to thank Prof. R. Billardon, Dr. C. Denoual, Profs. J. Lemaitre, D. Marquis, J. Mazars, Mr. S. Mencacci, Profs. S.P.B. Proença and S. Roux for useful and stimulating discussions.

\section{References}

Aveston J., Cooper G.A., Kelly A., " Single and Multiple Fracture », National Physical Laboratory: Properties of Fiber Composites, 1971, IPC Science and Technology Press, Surrey (UK), p. 15-26.

Aveston J., Kelly A., « Theory of Multiple Fracture of Fibrous Composites », J. Mater. Sci., vol. 8,1973 , p. 352-362. 
Balaguru P.N., Shah S.P., «Fiber Reinforced Cement Composite », McGraw Hill, New York (USA), 1992.

Batdorf S.B., Crose J.G., «A Statistical Theory for the Fracture of Brittle Structures Subjected to Polyaxial Stress States », ASME J. Appl. Mech., vol. 41, 1974, p. 459-465.

Beremin F.M., «A Local Criterion for Cleavage Fracture of a Nuclear Pressure Vessel Steel », Metallurgical Transactions A, vol. 14A, 1983, p. 2277-2287.

Bluhm J.I., « Fracture Arrest », Fracture, Academic Press, New York (USA), vol. V, 1969, p. $1-63$.

Brajer X., Hild F., Roux S., Gy R., « Behavior of soda-lime glasses impacted by a soft bullet: experimental and numerical investigations ", 14th Dymat Technical Meeting, 2002, EURODYMAT, p. 35-44.

Brara A., Klepaczko J., « An Experimental Method for Dynamic Tensile Testing of Concrete by Spalling », Int. J. Impact Eng., vol. 25, 2001, p. 387-409.

Camacho G.T., Ortiz M., « Computational Modelling of Impact Damage in Brittle Materials », Int. J. Solids Struct., vol. 33, no. 20-22, 1996, p. 2899-2938.

Davies D.G.S., « The Statistical Approach to Engineering Design in Ceramics », Proc. Brit. Ceram. Soc., vol. 22, 1973, p. 429-452.

Denoual C., Barbier G., Hild F., « A Probabilistic Approach for Fragmentation of Ceramics under Impact Loading », C. R. Acad. Sci. Paris, vol. 325, Série IIb, 1997, p. 685-691.

Denoual C., Cottenot C.E., Hild F., « On the Identification of Damage during Impact of a Ceramic by a Hard Projectile », 16th International Conference on BALLISTICS, 1996, APDS, Arlington (USA), p. 541-550.

Denoual C., Cottenot C.E., Hild F., " Analysis of the Degradation Mechanisms in an Impacted Ceramic », Shock Compression of Condensed Matter, 1998a, AIP Press, New York (USA), p. 427-430.

Denoual C., Hild F., « On the Characteristic Scales involved in a Fragmentation Process », J. Phys., vol. IV, no. 8, 1998b, p. 119-126.

Denoual C., Hild F., « A Damage Model for the Dynamic Fragmentation of Brittle Solids », Comp. Meth. Appl. Mech. Eng., vol. 183, 2000, p. 247-258.

Denoual C., Hild F., « Dynamic Fragmentation of Brittle Solids: A Multi-Scale Model », Eur. J. Mech. A/Solids, vol. 21, no. 1, 2002, p. 105-120.

Denoual C., Riou P., Comportement à l'impact de céramiques techniques pour blindages légers, CREA, Report 95 R 005, 1995.

Dugat J., Roux N., Bernier G., " Mechanical properties of reactive powder concretes », Mat. Struct., vol. 29, 1996, p. 233-240.

El Debs M.K., « Concreto pré-moldado : fundamentos e applicações », Projeto Reenge, São Carlos, EESC-USP (Brasil), 2000.

Evans A.G., " A General Approach for the Statistical Analysis of Multiaxial Fracture », $J$. Am. Ceram. Soc., vol. 61, no. 7-8, 1978, p. 302-308. 
30 Nom de la revue. Volume $\mathrm{X}-\mathrm{n}^{\circ} \mathrm{X} / 2002$

Freudenthal A.M., " Statistical Approach to Brittle Fracture », Fracture, Academic Press, New York (USA), vol. II, 1968, p. 591-619.

Freund L.B., " Crack Propagation in an Elastic Solid Subjected to General Loading Constant Rate of Extension », J. Mech. Phys. Solids, vol. 20, 1972, p. 129-140.

Grady D.E., Kipp M.E., « Continuum Modeling of Explosive Fracture in Oil Shale », Int. J. Rock Min. Sci. \& Geomech. Abstr., vol. 17, 1980, p. 147-157.

Grare L., Approche expérimentale et numérique de l'abattage de roches, B.Sc. report, ENS de Cachan, 2002.

Gulino R., Phoenix S.L., «Weibull Strength Statistics for Graphite Fibres Measured from the Break Progression in a Model Graphite/Glass/Epoxy Microcomposite », J. Mater. Sci., vol. 26, no. 11, 1991, p. 3107-3118.

Gy R., Guillemet C., " Characterization of a mode of rupture of glass at $610^{\circ} \mathrm{C}$ », The Physics of Non-Crystalline Solids, Taylor \& Francis, London (UK), 1992.

Hanai J.B., El Debs M.K., « The Future of Ferrocement in Civil Engineering. », Ferrocement (Proceedings of the Vth Int. Symposium on Ferrocement, Manchester (UK), 6-9 sept. 1994), 1994, E\&FN SPON, London (UK), p. 17-26.

Hild F., « Endommagement, rupture et changements d'échelles dans les matériaux hétérogènes », mémoire d'Habilitation à Diriger des Recherches, Université Paris 6 (in French), 1998.

Hild F., « Probabilistic Approach to Fracture: the Weibull Model », Handbook of Materials Behavior Models, Academic Press, San Diego (USA), vol. 2, 2001, p. 558-565.

Hild F., Billardon R., Marquis D., « Hétérogénéité des contraintes et rupture des matériaux fragiles », C. R. Acad. Sci. Paris, vol. 315, Série II, 1992a, p. 1293-1298.

Hild F., Brajer X., Denoual C., Forquin P., « On the Probabilistic-Deterministic Transition Involved in a Fragmentation Process of Brittle Materials », Comput. Struct., in press, 2003.

Hild F., Marquis D., « A Statistical Approach to the Rupture of Brittle Materials », Eur. $J$. Mech., A/Solids, vol. 11, no. 6, 1992b, p. 753-765.

Hornemann U., Kalthoff J.F., Rothenhäusler H., Senf H., Winkler S., Experimental Investigation of Wave and Fracture Propagation in Glass - Slabs Loaded by Steel Cylinders at High Impact Velocities, EMI report E 4/84, Weil am Rhein (Germany), 1984.

Jayatilaka A. de S., Trustrum K., « Statistical Approach to Brittle Fracture », J. Mater. Sci., vol. 12, 1977, p. 1426-1430.

Jeulin D., « Modèles morphologiques de structures aléatoires et changement d'échelle », thèse d'État, Université de Caen (in French), 1991.

Kadlecek V., Spetla Z., «Effect of Size and Shape of Test Specimens on the Direct Tensile Strength of Concrete », Bull. RILEM, vol. 36, 1967, p. 175-184.

Kennedy R.P., «A Review of Procedures for the Analysis and Design of Concrete Structures to Resist Missile Impact Effects », Nucl. Eng. Des., vol. 37, 1976, p. 183-203. 
Kutter H.K., Fairhurst C., " On the Fracture Process in Blasting », Int. J. Rock Mech. Min. Sci., vol. 8, 1971, p. 181-202.

Lambot J.L., «Ferciment », French patent, 1855.

Lamon J., Evans A.G., « Statistical Analysis of Bending Strengths for Brittle Solids: a Multiaxial Fracture Problem », J. Am. Ceram. Soc., vol. 66, no. 3, 1983, p. 177-182.

L'Hermite S., « Influence de la dimension absolue sur la résistance de flexion », Annales de l'I.T.B.T.P., vol. 309-310, 1973, p. 39-41.

Marrey B., «Les ponts modernes - vingtième siècle », Picard éditeurs, Paris (France), 1995.

Mastilovic S., Krajcinovic D., « High-Velocity Expansion of a Cavity within a Brittle Material », J. Mech. Phys. Solids, vol. 47, 1999, p. 577-600.

Munz D., Fett T., « Ceramics. Mechanical Properties, Failure Behavior, Materials Selection », Springer, Berlin, 1999.

Naaman A.E., «Ferrocement and Laminated Cementious Composites », Techno Press 3000, Ann Arbor (USA), 2000.

Nervi P.L., « Il ferro-cemento : sue caratteristiche e possibilità », L'ingegniere, vol. 25, no. 1, 1951, p. $17-25$.

Richard P., Cheyrezy M., « Composition of reactive power concretes », Cement Conc. Res., vol. 25 , no. 7,1995 , p. 1501-1511.

Rinehart J.S., « Dynamic Fracture Strengths of Rocks », 7th Symp. Rock Mech., 1965.

Riou P., Denoual C., Cottenot C.E., « Visualization of the Damage Evolution in Impacted Silicon Carbide Ceramics », Int. J. Impact Eng., vol. 21, no. 4, 1998, p. 225-235.

Shockey D.A., Curran D.R., Seaman L., Rosenberg J.T., Petersen C.F., « Fragmentation of Rocks under Dynamic Loads », Int. J. Rock Mech. Min. Sci., vol. 11, 1974, p. 303-317.

Silva A.R.C., « Uma abordagem probabilista de ruptura de painéis tracionados de concreto de granulometria fina armados com telas soldadas », $\mathrm{PhD}$ thesis, University of São Paulo (in Portuguese), 2002.

Strassburger E., Senf H., Rothenhäusler H., « Fracture Propagation during Impact in Three Types of Ceramics », J. Physique IV, vol. coll. C8, no. suppl. IV, 1994, p. 653-658.

Weibull W., A Statistical Theory of the Strength of Materials, Roy. Swed. Inst. Eng. Res. $151,1939$.

Weibull W., " A Statistical Distribution Function of Wide Applicability », ASME J. Appl. Mech., vol. 18, no. 3, 1951, p. 293-297. 